\title{
Metodilla on merkitys - muodolla on mieli
}

\section{Draamatyöskentely mielenterveyshoitotyön ammattikorkeakouluopinnoissa}

"Siinä me istuttiin koko porukka näyttämön reunalla, aikuiset miehet ja naiset ja pohdittiin vakavissamme Pinokkio-satua. Puisen nuken kasvua eläväksi ja tuntevaksi ihmiseksi. Yht äkkiä joku tokas: ”Täähän on tarina meidän työelämästä. Siitä, kun psyykkisesti sairas ihminen alkaa taas elään.” Siinähän se oli koko jutun ydin ja kello oli seitsemän...illalla. Eikä kenelläkään ollut kiirettä kotiin.”

Tämä on ote opiskelijan opintopäiväkirjasta ajalta, jolloin kymmenen opiskelijan ryhmä, viisi naista ja viisi miestä tutkivat opinnäytetyönään lapsen moraalikehitystä forumteatterin keinoin.

Parhaimmillaan opiskelu on kokemuksena juuri tällaista. Oivaltaminen on vaivatonta, nautinnollista ja innostavaa. Ajattelu noukkii metaforisesta fiktiosta aineksia ja liittää ne intuitiivisesti todelliseen elämään. Aika kadottaa merkityksensä. Ajattelu virtaa ja tempaa mukaansa ryhmän. Tätä kokemusta on opittu kutsumaan "flowksi". Kokonaisvaltainen oppimiskokemus jättää meihin syvän jäljen. Miten kokonaisvaltaisia oppimiskokemuksia voisi luoda ja mikä niiden merkitys on ammattiin kasvussa?

Ammattikorkeakoulut syntyivät kasvatustieteelliseen ajankohtaan, jolloin ns. kasvatuksen uusi paradigma oli tuonut tutkimuksen keskiöön opiskelijan ja oppimisen. Myös tekniikan voimakas mukaantulo opetukseen heijastui tutkimuksissa. Ammattikorkeakoulujen syntyvaiheissa otettiin etäisyyttä ammatilliseen opistoasteeseen ja yliopistoon tiedekorkeakouluna. Anglosaksinen pedagogiikkaperinne siirtyi vaivatta myös ammattikorkeakouluihin. Didaktiikka käsitteenä katosi tutkimuksesta ja opetuksen käytänteistä.

Ammattikorkeakoulupedagogiikka painottaa propositionaalista tietoa. Opiskelusta on tullut paperinmakuista tai pitäisikö sanoa päätteen hajuista. Tiedon hallintaa mitataan ammatillisena osaamisena.Vaikka tiedolla on suuri merkitys ammattitaidolle, se ei kuitenkaan ole riittävä ammatissa osaamisen tae. Tarvitaan taitoja, ymmärrystä ja viisautta. Ihmissuhdetyön ammateissa tarvitaan erityisesti kykyä eläytyä, kuulla ja kuunnella, olla läsnä ja osata toimia yhteistyössä muiden kanssa.

Ammatillisen koulutuksen maailmassa vallitsee mielenkiintoinen

paradoksi:

Opiskelua, siis opiskelijan perustehtävään liittyvää, leimaa vahva yksilöllisten valintavaihtoehtojen ja vapauden ideologia. Taustalla näyttäisi heijastelevan länsimaisen ajattelumme idealistinen ihanne ihmisestä riippumattomana ja itsenäisenä. Se on antanut perustan etäopiskelulle, jonka luonnetta Kuusi (2004) kutsuu "etäläsnäoloksi”. Itseohjautuvuus opiskelussa on alkanut muistuttaa itsepalvelutoimintaa. Opiskelu opetuspalveluiden käyttämisenä on johtanut siihen, että opiskelijoita on ajoittain kutsuttu myös asiakkaiksi.

Toisaalta erilaiset standardit ja tuotteistetut toimintamallit ohjaavat yhä enemmän opetusta, siis opettajan perustehtävää. Näin opetus myös yhdenmukaistuu ja samankaltaistuu riippumatta eri ammattialojen sisällöistä ja vaatimuksista. Opetuksen käsite on myös katoamassa. Opetuksesta on tullut ohjaamista, tutorointia, oppimisalustojen ja -ympäristöjen rakentamista.

Miten on mahdollista että ammattiin kasvattajat ammattikasvatuksen käytännön asiantuntijoina, ovat luovuttaneet työnsä autonomisimman alueen? Didaktinen ajattelu ja valinnat ovat kuitenkin opettajan ammatillisen erityisosaamisen luovinta aluetta. Opetus on opettajan arjen taidet- 
ta. Didaktisessa toiminnassa paljastuu myös opettajan persoonallinen käyttöteoria.

Jokaiseen ammattiin kasvu edellyttää sille optimaalisia opetus- ja oppimisprosesseja. Ihmissuhdetaitojen ammatillisessa koulutuksessa keskeistä on harjaantuminen dialogitaidoissa, jotta ihmisten välisistä suhteista voisi tulla auttavaa toimintaa. Mielenterveyshoitotyössä ammatillisen osaamisen ydin on psykoterapeuttisissa valmiuksissa. Yleiset vuorovaikutustaidot eivät silloin riitä. Tarvitaan teoreettista tietoa ihmisestä yleensä ja ennen muuta riittävää itsetuntemusta. Psykoterapeuttisia valmiuksia ovat esimerkiksi eläytymis-, läsnäolo- ja yhteistyötaidot. Harjaantuminen näissä taidoissa on ammatillisen ihmissuhdekoulutuksen vaikeimpia haasteita. Vastausta kysymyksen: ”Mitä on masennus?” on etsittävä erilaisin keinoin kuin vastausta kysymykseen: ”Mitä on olla masentunut?” Jälkimäinen kysymys on kuitenkin hoitotyössä keskeisin. Ihmissuhteita voidaan oppia vain ihmissuhteissa. Opiskeluryhmä ja opettaja toimivat yksittäiselle opiskelijalle jatkuvan palautteen ja reflektion peilinä.

Ammattikorkeakoulut ihmissuhdetyön ammatillisen oppimisen paikkana ovat Wengerin (2002) kuvaamia käytännön yhteisöjä. Niissä etenkin hiljaista tietoa edustavat mentaaliset toimintatavat siirtyvät tuleviin työorganisaatioihin. Opiskelussa jokainen kohtaaminen on hoitotyön potentiaalinen tilanne ja siten ammattikäytännön opiskelua.

Tekniikan kehitys mahdollistaa tiedon nopean siirtymisen ja prosessoinnin. Tutkimusten mukaan ammattikorkeakouluopettajat ja opiskelijat ovat yhteydessä toisiinsa ennen muuta kirjoitettujen tekstien välityksellä. (Auvinen 2004.) Tämä kertoo ammattikorkeakoulujen vallitsevasta tietokäsityksestä. Elämme vahvan arviointikulttuurin aikakautta. Arviointi on ymmärretty yhteneväksi kehittämisen kanssa. Arvioinnin kohteena on ennen muuta opiskelijan kirjoitetut tekstit, sillä niitä on helpointa arvioida. Mentaaliset alueet oppimisessa ovat vaikeimmin arvioitavia. Niiden opiskelu on hidasta kehkeytymistä ja olennaisessa viipyilyä. Kun opiskelun sisältönä on ihmisten välinen dialogi se edellyttää kykyä luopua jatkuvasta yrityksestä ymmärtää toista selittämisen kautta. Toista ihmistä kun emme voikaan ymmärtää. Sennetin ( 2004 ) mukaan sitä mitä emme voi ymmärtää, voimme vain kunnioittaa. Tämä ymmärtämisen pakosta luopuminen on vaikea oppimisen vaihe auttamistyöhön haluaville opiskelijoille.
Kyse on syvästä itsetuntemukseen ja rajallisuuteen liittyvästä oivalluksesta, joka johtaa kykyyn tehdä ero itsen ja toisen välillä.

Ammattikorkeakoulujen kulttuurinen tehtävä on ammattiin kasvun alkuun saattaminen. Todelliset ammattien taitajat kehittyvät vuosien kuluessa. Alulle saattamisen tehtävä on vastuullinen ja vaativa. Ammatillisen polun alkuvaiheessa jäljen jättävät oppimiskokemukset ovat merkityksellisiä. Ne koskettavat koko persoonaa ja antavat mahdollisuuden myös tunteiden kokemiseen. Tunteet puolestaan aukaisevat yhteyden toimintaa ohjaaviin arvoihin ja niiden käsittelyyn. Siksi tunteilla on keskeinen osuus eettisesti sitoutuneessa hoitotyön koulutuksessa. Taiteilla on suora yhteys tunteisiin. Ne avaavat sanoille ulottumatonta. Bergsonin $(1994,124)$ mukaan ”Taide ei varmastikaan ole muuta kuin suorempi näköyhteys todellisuuteen.” Taide (kreikan tekhne ja latinan ars) on alkuperäisesti kuulunut taidon yhteyteen, jonne sen yhä soisi selkeämmin kuuluvan. Taiteella on omintakeinen tapa tietää ja resonoida totuuden ja hyvyyden kanssa.

Draama ja osallistava teatteri didaktisena muotona ovat pragmatistista taidetta. Hoitotyön koulutuksessa niiden esteettisyys kietoutuu eettisyyteen.

Tutkimukseni kiinnostuksen kohteena oli didaktisen valinnan merkitys ammattiin kasvussa. Didaktisena valintana tutkimuksessa oli draama ja opiskelun kohteena mielenterveyshoitotyö. Keskeisenä tuloksena tutkimuksessa nousee ryhmän vahva merkitys oppimiselle. Draama didaktisena valintana näyttäisi lisäävän itsetuntemusta, kehittävän läsnäolotaitoa ja eläytymiseen perustuvaa empatiataitoa sekä yhteistyötaitoja. Riittävän pitkäkestoinen ryhmä mahdollistaa myös ongelmien ja ristiriitojen kohtaamisen ja selvittämisen. Opiskelijaryhmä toimii silloin analogisena tulevan työyhteisön kanssa. Tutkimuksen tuloksena syntyi draaman ontologista erittelyä. Draama näyttäisi rikkovan transferille oletetun kenttäriippuvuuden kuljettaessaan fiktiivisessä, mahdollisissa maailmoissa, opittua ja oivallettua faktiseen maailmaan. Fiktiivisen ja faktisen välimaastossa oppimisen ajatellaan tapahtuvan juuri niiden samanaikaisessa läsnäolossa. Tätä kaksoistietoisuutta Boal (1996) kutsuu metaxikseksi.

Yleisenä päätelmänä tutkimuksesta voidaan sanoa: valitessaan opetuksen didaktisen menetelmän opettaja valitsee myös metodin taustalla olevan muodon ontologian. Opettajan ammattitai- 
toa on tunnistaa minkälaiseen ajatteluun ihmisestä, elämästä, maailmasta ja oppimisesta opetuksen metodi nojaa. Opettajankoulutuksella on tässä haasteellinen tehtävä. Miten avata ja laajentaa tulevien opettajien didaktista ajattelua ja toimintaa oppimisen edistämiseksi. Myös ammattikorkeakoulujen pedagoginen kehittäminen tarvitsee monipuolista, luovaa ja rikasta didaktista tutkimusta, kehittämistä ja moninaisten opetusmenetelmien arvostamista. Opetuksen menetelmien aliarviointi merkitsee menetelmiin sisältyvien oppimispotentiaalien kadottamista. McLuhaniin (1984) viitaten: ”Välineellä on viesti.” Opetuksen muoto kantaa sisältöä, joten sen tulee olla mielellisessä suhteessa tarkoitettuihin oppimistavoitteisiin.

\section{Viittaukset}

Auvinen, P. (2004). Ammatillisen käytännön toistajat monipuoliseksi aluekehittäjäksi? Ammattikorkeakoulu-uudistus ja opettajan työn muutos vuosina 1992-2010. Joensuun yliopiston kasvatustieteellisiä julkaisuja: 100 .

Bergson, H. (1994). Nauru. Tutkimus komiikan merkityksestä. Helsinki: Loki-kirjat

Boal, A. (1996). Politics, education and change. Teoksessa Drama, Culture and Empowerment. Brisbane. IDEA Publications, 47-52.

Kuusi, O. (2004). Etäläsnäoloa. Teoksessa J. Heinonen \& G. Hertzen \& O. Kuusi (toim.) NYT on ennen huomista. Ekosäätiö.

McLuhan, M. (1984). Ihmisen uudet ulottuvuudet. Kolmas painos. Helsinki: WSOY

Sennett, R. (2004). Kunnioitus eriarvoisuuden maailmassa. Tampere:Vastapaino

\section{Annukka Häkämies}

Kasvatustieteen väitös Tampereen yliopistossa 13.10.07 Lectio praecursoria 